\title{
Potencial antiinflamatório de Annona glabra, Annonaceae
}

\author{
Christian A. Siebra, ${ }^{1}$ Jeanine M. Nardin, ${ }^{1}$ Angela Florão, ${ }^{1}$ Fabiana H. Rocha, ${ }^{2}$ Denise Z. \\ Bastos, ${ }^{3}$ Brás H. Oliveira, ${ }^{1,3}$ Almeriane M. Weffort-Santos $*, 1,4$
}

\author{
${ }^{1}$ Programa de Pós-Graduação em Ciências Farmacêuticas, Universidade Federal do Paraná. Av. Prefeito \\ Lothário Meissner, $632 \mathrm{Jd}$. Botânico, 80210-170 Curitiba-PR, Brasil, \\ ${ }^{2}$ Curso de Farmacia, Universidade Federal do Paraná, Av. Prefeito Lothário Meissner, 632 Jd. Botânico, 80210- \\ 170 Curitiba-PR, Brasil, \\ ${ }^{3}$ Programa de Pós-graduação em Química, Universidade Federal do Paraná, Centro Politécnico, Caixa Postal \\ 19081, Jardim das Américas, 81531-990 Curitiba-PR, Brasil, \\ 4," Departamento de Patologia Médica, Curso de Farmacia, Universidade Federal do Paraná, Av. Prefeito \\ Lothário Meissner, 632 Jd. Botânico, 80210-170 Curitiba-PR, Brasil
}

\begin{abstract}
RESUMO: Annona glabra Linneau, Annonaceae, é uma árvore de pequeno porte encontrada em todo território brasileiro, principalmente nas áreas costeiras e conhecida popularmente como araticum-do-brejo e araticum-bravo. Este trabalho teve como objetivos investigar os efeitos do extrato de $A$. glabra e do ácido caurenóico dele purificado sobre a migração de granulócitos humanos e seu potencial imunomodulatório. Os resultados demonstraram que o extrato de $A$. glabra inibe a migração natural de granulócitos, de acordo com a dose, sugerindo potencial antiinflamatório, enquanto o ácido caurenóico demonstrou estimulá-la de forma significativa. Em contraste, nenhum efeito foi observado com relação a imunomodulação. Os efeitos apresentados ainda não foram descritos e, dessa forma, contribuem para ampliar a lista de atividades biológicas descritas não só do extrato de $A$. glabra, como também para o ácido caurenóico.
\end{abstract}

Unitermos: Annona glabra, Annonaceae, ácido caurenóico, leucócitos humanos, quimiotaxia, imunomodulação.

\begin{abstract}
Anti-inflammatory potential of Annona glabra, Annonaceae". Annona glabra Linneau, Annonaceae, is a small tree that grows over the Brazilian territory particularly in its coast, and is known as "araticum-do-brejo" and "araticum-bravo". The aim of this study was to evaluate the effects of the extract of $A$. glabra and its purified kaurenoic acid on the locomotion of human granulocytes and their immunomodulatory potential. The results herein presented showed a dose-dependent inhibition of the granulocyte migration for the extract, suggesting an anti-inflammatory activity, in contrast with a striking stimulation observed for the kaurenoic acid. When focusing immunomodulation properties, no activity could be drawn. The effects presented in this work are reported for the first time and extend the list of biological activities already described for the A. glabra extract as well as for the kaurenoic acid.
\end{abstract}

Keywords: Annona glabra, Annonaceae, kaurenoic acid, human leukocytes, chemotaxis, immunomodulation.

\section{INTRODUÇÃO}

A família Annonaceae, de distribuição pantropical, tem cerca de 110 gêneros e aproximadamente 2.150 espécies identificadas (Mabberley, 1997). No Brasil, já foram registrados 29 gêneros, com cerca de 260 espécies (Barroso et al., 1978) e, dentre elas está a Annona glabra Linneau. Quimicamente é uma das famílias de plantas tropicais menos estudadas. Entretanto, investigações fitoquímicas e farmacológicas sobre membros desta família vêm se intensificando nos últimos anos (Lima et al., 2006; Nascimento et al., 2006; Moreira et al., 2007; Ribeiro et al., 2007; Cardoso-Lopes et al., 2008; Costa et al., 2008; Valter et al., 2008).

Estudos sobre a A. glabra, comumente conhecida no Brasil como araticum-do-brejo e araticum-bravo, têm demonstrado grande quantidade de compostos de natureza química diversificada nas mais variadas partes da planta. Os principais grupos de compostos presentes em extratos preparados de cascas (Oliveira et al., 2002), caules (Chen et al., 2004), folhas (Oliveira et al., 2002) e frutos (Chang et al., 1998; Chen et al., 2004) são os alcalóides, as acetogeninas e os diterpenos. Dentre estes, o ácido caurenóico (I), ou ácido caur-ent-16-en19-oico, é um dos mais estudados, para o qual várias atividades biológicas já foram descritas, desde a inibição 
da replicação do vírus HIV em linfócitos (Chang et al., 1998), como agente citotóxico (Costa-Lotufo et al., 2002; Zhang et al., 2004), trypanosomicida (Alves et al., 1995; Vieira et al., 2002), larvicida (Slimestrad et al., 1995), antimicrobiano (Padmaja et al., 1995; Velikova et al., 2000), vermífugo, esporicida (Padmaja et al., 1995), analgésico (Block et al., 1998), contraceptivo (Page et al., 1992), relaxante da musculatura lisa vascular aórtica de ratos (Tirapelli et al., 2004), até como agente antiinflamatório (Paiva et al., 2002).

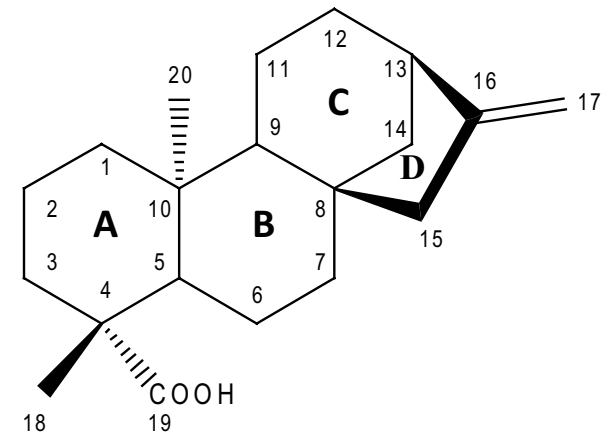

I

Como não há relatos sobre o potencial do extrato de $A$. glabra em interferir nas respostas inflamatória e imune, o objetivo deste trabalho foi o de investigar seu potencial sobre a migração de granulócitos, uma atividade fundamental dessas células durante a resposta inflamatória. Uma vez que, após a instalação de um agente patogênico, o organismo reage para a eliminação do mesmo numa ação integrada entre os fagócitos, protagonistas da reação inflamatória, e as células do sistema imunológico, investigou-se também o seu potencial imunomodulador. Ainda, investigar simultaneamente o comportamento do ácido caurenóico dele purificado, uma vez que o mesmo tem sido alvo de estudos de modificações estruturais no esqueleto caurânico com o objetivo de se obter substâncias bioativas (Garcia et al., 2007).

\section{MATERIAL E MÉTODOS}

\section{Material botânico, preparação do extrato e obtenção do ácido caurenóico}

Cascas de Annona glabra foram coletadas nas proximidades de Antonina, Paraná, em abril de 1997 e identificadas pelo Professor O. Guimarães, Depto de Botânica da UFPR. Uma exsicata encontra-se depositada no herbário da UFPR sob Protocolo UPCB 40.105. Os processos para a obtenção do extrato e do ácido caurenóico foram exatamente os descritos por Oliveira et al. (2002). Soluções de ambos foram preparadas em RPMI 1640 (Himedia, Mumbai, Índia), esterilizadas por filtração (0,22 $\mu \mathrm{m}$ - Acrodisc), aliquotadas e mantidas a $-20^{\circ} \mathrm{C}$ até o momento do uso.

\section{Obtenção de leucócitos humanos e isolamento de sub-frações}

Dez a vinte mililitros de sangue venoso heparinizado, colhidos assepticamente de voluntários sem manifestação de sinais ou sintomas de doença e sem uso de medicamentos, foram utilizados como fonte de células humanas. As amostras foram obtidas após consentimento livre e esclarecido, aprovado pelo Comitê de Ética em Pesquisas em Seres Humanos do Setor de Saúde da Universidade Federal do Paraná, sob registro CEP/SD 039.SI.003/04-01. Os protocolos utilizados para a obtenção de células mononucleares (MNC) e de granulócitos (GNC) foram essencialmente como os descritos, respectivamente, por Machado-Jr. et al. (2006) e Presibella (2006). Citocentrifugados preparados das frações de MNC utilizadas demonstraram a presença de $80-95 \%$ de linfócitos e $5-20 \%$ de monócitos. Para a fração de GNC, observou-se que mais de $99 \%$ era constituída por neutrófilos, com raros eosinófilos.

\section{Testes de viabilidade e toxicidade}

A viabilidade dos leucócitos foi avaliada após o processo de isolamento e durante todas as etapas dos procedimentos metodológicos. Para tanto, usou-se o teste com azul de tripano (Merchant et al., 1964). Sub-frações de células foram diluídas apropriadamente em solução de azul de tripano $0,4 \%$ e sua viabilidade observada ao microscópio comum. As células discriminadas como viáveis apresentaram-se íntegras, brilhantes, incolores e redondas, enquanto que as não viáveis mostraramse coradas em azul, muitas com perda da definição de contorno. A toxicidade do extrato de $A$. glabra e do ácido caurenóico foi avaliada, respectivamente, para as concentrações de 0,01 a $100 \mu \mathrm{g} / \mathrm{ml}$ e de 0,01 a $100 \mu \mathrm{M}$. Para $\mathrm{MNC}$, as amostras foram incubadas por 5 dias, a $37^{\circ} \mathrm{C}$, em atmosfera de $5-10 \%$ de $\mathrm{CO}_{2}$. Para GNC, as amostras foram incubadas a $37^{\circ} \mathrm{C}$, por 2 e 5 horas.

\section{Citocentrifugados}

Para observação da composição das sub-frações de leucócitos, lâminas contendo $8 \times 10^{4}$ células foram preparadas por centrifugação a $250 \mathrm{~g}$ por cinco min em citocentrífuga Cytopro ${ }^{\circledR}$ (Wescor). Em seguida, os citocentrifugados secos ao ar foram corados com MayGrünwald-Giemsa e as populações celulares enumeradas e diferenciadas com auxílio de um microscópio comum. Fotomicrografias foram obtidas com auxílio do programa Image Pro Plus, versão 3.0.01.00 para Windows.

\section{Quimiotaxia}


Os ensaios de quimiotaxia foram realizados em câmaras de Boyden de acordo com o protocolo experimental descrito por Presibella et al. (2006). Os resultados estão expressos como a porcentagem média \pm um erro padrão da média (EPM) de células recuperadas do compartimento inferior das câmaras em relação aos resultados obtidos para a caseína, usada como controle positivo de migração. Citocentrifugados dessas células mostrou a presença de $>99 \%$ de neutrófilos.

\section{Imunomodulação}

Os ensaios de imunomodulação com a fração de MNC foram realizados essencialmente como descritos por Machado-Jr et al. (2006) e os resultados estão expressos como a média \pm um desvio padrão (DP). Citocentrifugados preparados após incubação com o extrato de $A$. glabra ou com o ácido caurenóico demonstraram a presença de 95 e $88 \%$ de linfócitos, respectivamente. $\mathrm{Na}$ presença concomitante de fitohemaglutinina (PHA), os valores de linfócitos foram, respectivamente, de 5,7 e 3,3\%, sendo o restante identificado como linfócitos ativados, ou linfoblastos.

\section{Estudos estatísticos}

Para análise estatística dos resultados, usouse ANOVA, one way; quando apropriado, o teste post hoc empregado foi o teste de Tukey. Os cálculos foram realizados utilizando-se o programa Statistica e valores de $p \leq 0,05$ foram considerados estatisticamente significativos.

\section{RESULTADOS}

Efeitos do extrato de $\boldsymbol{A}$. glabra e do ácido caurenóico sobre a migração de granulócitos

Como ilustrado na Figura 1, a porcentagem média de células que migraram para o compartimento inferior das câmaras de Boyden após exposição às doses indicadas do extrato de A. glabra foi dependente da concentração e menor do que a observada para a população controle $(22,6 \pm 1,8 \%)$, exposta somente ao PBS, com valores que variaram de $20,4 \pm 0,1$ a $13,8 \pm 3,6 \%$, sendo inclusive significativa a partir da dose de $0,1 \mu \mathrm{g} / \mathrm{ml}(\mathrm{n}=4 ; p<0,0001$ para todas as concentrações).

Em contraste, observou-se um aumento significativo de células recrutadas pelo gradiente de ácido caurenóico em relação à população controle (Figura 2), variando de $37,1 \pm 2,2 \%$, na dose de 0,001 $\mu \mathrm{M}$, a $27,7 \pm 2,9 \%$ a $0,1 \mu \mathrm{M}$ Entretanto, na dose de $1 \mu \mathrm{M}$, observou-se que somente $15,6 \pm 2,2 \%$ de GNC foram recuperados, demonstrando um efeito inibidor significativo da migração $(\mathrm{n}=4 ; p<0,0001$ para todos em relação ao controle). Importante ressaltar que os efeitos inibitórios observados não foram decorrentes de toxicidade sobre as células, uma vez que $>94 \%$ dos GNC mantiveram-se viáveis após cinco horas de incubação, independente da dose ou do tratamento imposto.

Mesmo tendo o efeito quimiotático apresentado pelo ácido caurenóico sido significativo em relação à população controle, é preciso notar que o mesmo foi inferior àquele demonstrado pela caseína, cuja diferença de intensidade pode ser melhor observada nas fotomicrografias das populações transmigradas, ilustradas na Figura 3. É relevante o fato de que a caseína é uma proteína do leite, cuja presença de receptores opióides (Goody \& Kitchen, 2001) já foi descrita tanto em granulócitos como em monócitos (Lewis \& Van Epps, 1983).

\section{Efeitos do extrato de $\boldsymbol{A}$. glabra e do ácido caurenóico sobre a imunomodulação}

Tendo-se observado competência tanto do extrato de A. glabra como do ácido caurenóico em interferir na migração de GNC, investigou-se, primeiro, seus efeitos sobre a ativação e a proliferação de linfócitos humanos presentes na fração de MNC, em seu estado basal. Com os resultados apresentados na Figura 4A, foi possível constatar que nenhuma das concentrações ensaiadas dessas substâncias interferiu na transformação blástica ou na proliferação de linfócitos, indicando que essas substâncias são desprovidas de atividade imunomoduladora, sendo incapazes de ativar linfócitos humanos e, como conseqüência, promover sua proliferação. Esses resultados foram confirmados pela análise citológica das populações após incubação, onde citocentrifugados corados mostraram que a grande maioria era constituída por linfócitos. Em experimentos semelhantes em que fitohemaglutinina foi adicionada concomitantemente (Figura 4B) com o objetivo de ativar previamente os linfócitos, também não foi evidenciado nenhum efeito imunomodulador.

\section{DISCUSSÃO}

$\mathrm{O}$ ensaio de quimiotaxia como proposto por Boyden no início dos anos 60 (Boyden, 1962) e suas variações tem se mostrado útil como uma metodologia in vitro para se investigar o efeito de extratos (Hofbauer et al., 2001; Ihantola-Vormisto et al., 1997; Presibella et al., 2007; Presibella et al., 2006) e de substâncias extraídas de plantas (Chen et al., 2001; Hofbauer et al., 1999; Muller et al., 1999) sobre a quimiotaxia de leucócitos. Neste trabalho, investigou-se o potencial do extrato de $A$. glabra e de seu ácido caurenóico no recrutamento de GNC de sangue periférico utilizando-se câmaras de Boyden. Para tanto, essas substâncias foram adicionadas ao compartimento inferior das câmaras, separado do superior por filtros de policarbonato contendo poros de $5 \mu \mathrm{m}$ de diâmetro. Para fins de 


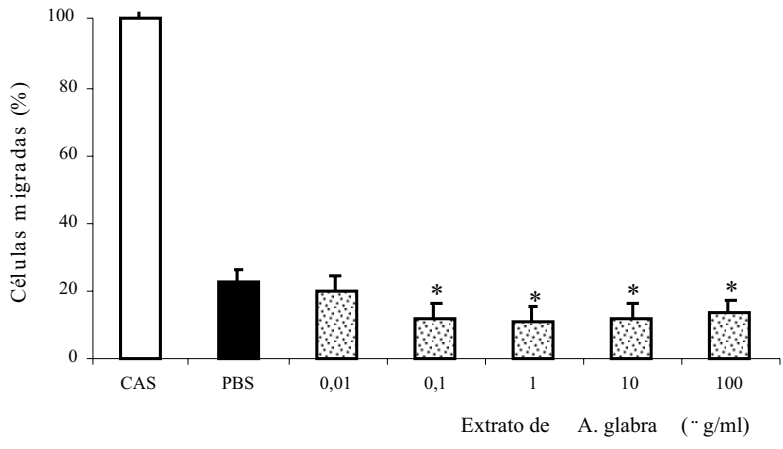

Figura 1. Efeitos do extrato de A. glabra sobre a quimiotaxia de granulócitos humanos. Granulócitos obtidos de sangue periférico de doadores sadios foram expostos às concentrações indicadas do extrato de $A$. glabra, adicionadas ao compartimento inferior de câmaras de Boyden, e estimulados a migrar por noventa minutos, a $37^{\circ} \mathrm{C}$. As colunas representam a porcentagem média \pm EPM de células recuperadas do compartimento inferior da câmara em relação à população controle exposta à caseína (CAS), para a qual os dados foram normalizados em 100\%; $\left.(\mathrm{n}=4) ;{ }^{*}\right] p<0,0001$ (ANOVA, seguida do teste de Tukey).

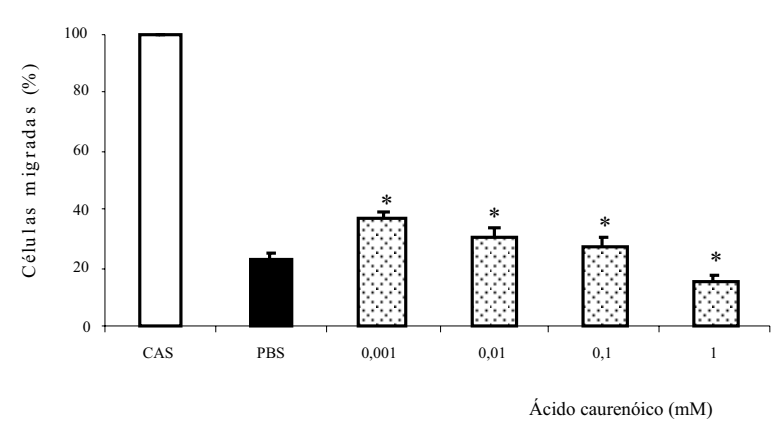

Figura 2. Efeitos do ácido caurenóico sobre a quimiotaxia de granulócitos humanos. Granulócitos obtidos de sangue periférico de doadores sadios foram expostos às concentrações indicadas do ácido caurenóico purificado de extrato de $A$. glabra, adicionadas ao compartimento inferior de câmaras de Boyden, e estimulados a migrar por noventa minutos, a 37 ${ }^{\circ} \mathrm{C}$. As colunas representam a porcentagem média \pm EPM de células recuperadas do compartimento inferior da câmara em relação à população controle exposta à caseína (CAS), para a qual os dados foram normalizados em 100\%; $(\mathrm{n}=4) ;\left[{ }^{*}\right] p<$ 0,0001 (ANOVA, seguida do teste de Tukey).
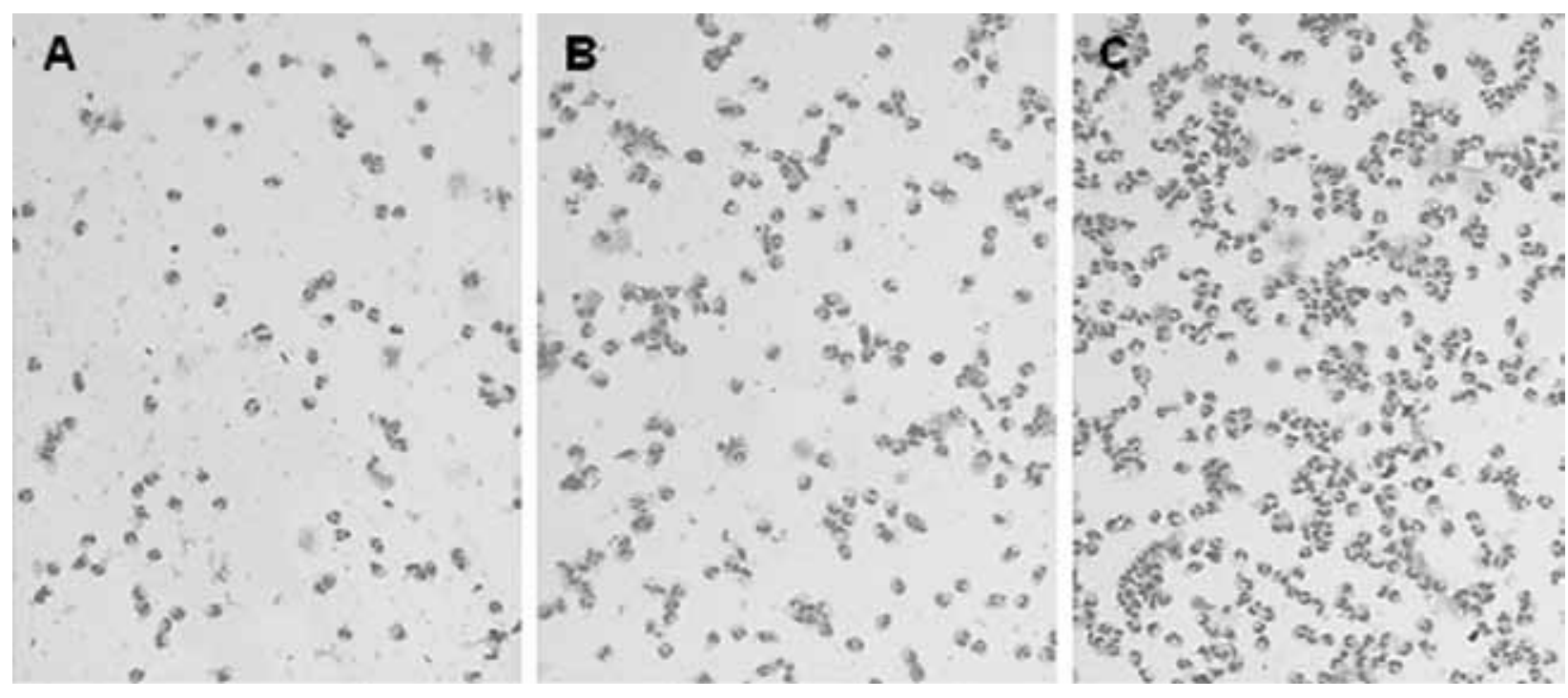

Figura 3. Análise morfológica das populações de granulócitos após exposição ao gradiente de ácido caurenóico. Citocentrifugados corados com May-Grunwald-Giemsa obtidos das populações recuperadas do compartimento inferior das câmaras de Boyden após exposição, por noventa minutos a $37^{\circ} \mathrm{C}$, aos gradientes de PBS (A), 0,01 $\mu \mathrm{M}$ de ácido caurenóico (B) e caseína (C), usada como controle positivo da migração, demonstrando a presença majoritária de granulócitos neutrófilos (x100).

comparação de efeito, utilizou-se a caseína, uma proteína reconhecidamente dotada de potente atividade quimiotática sobre GNC humanos (McCutcheon, 1955; Solymossy et al., 1986), para a qual os dados foram normalizados em $100 \%$.

Os resultados apresentados demonstraram que o extrato de A. glabra tem a habilidade de inibir significativamente a migração de GNC humanos de forma dose-dependente, enquanto o ácido caurenóico dele purificado é dotado de uma significativa ação estimulante da migração a favor de seu gradiente em baixas concentrações, agindo como um fator quimioatrator. Neste contexto, o relato de que ratos portadores de colite induzida por ácido acético, previamente tratados com ácido caurenóico purificado de Copaifera langsdorffii, demonstraram redução da inflamação associada a um aumento da atividade da mieloperoxidase (Paiva et al., 2002), uma enzima 


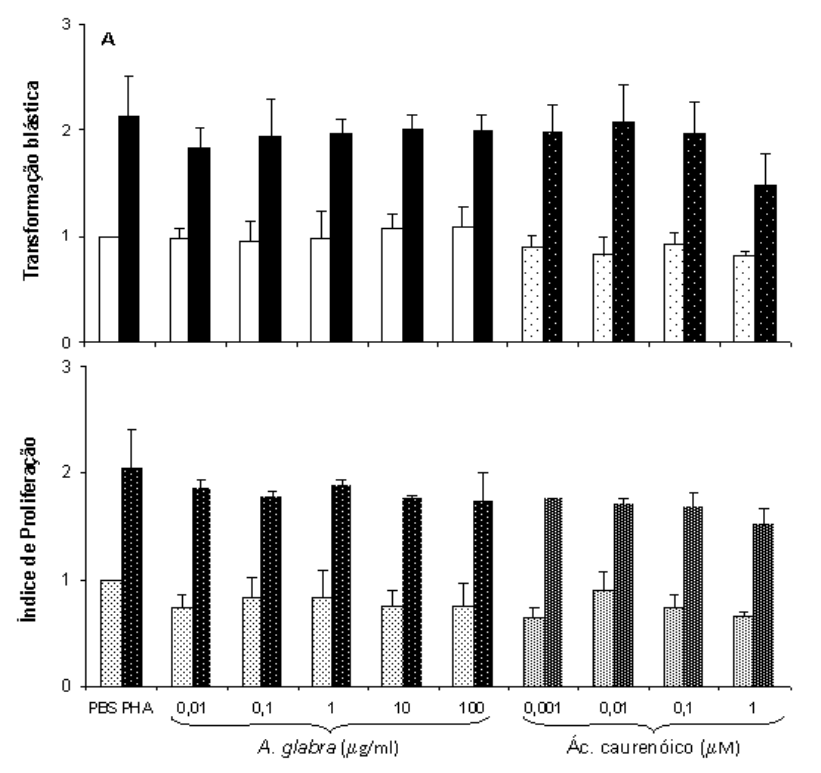

Figura 4. Efeitos do extrato de A. glabra e do ácido caurenóico sobre a transformação blástica e a proliferação de linfócitos humanos. Mononucleares obtidos de sangue periférico foram cultivados por 5 dias, a $37{ }^{\circ} \mathrm{C}$, em atmosfera de $5 \%$ de $\mathrm{CO}_{2}$ com as concentrações indicadas do extrato de A. glabra e do ácido caurenóico. Cada coluna em (A) representa a média \pm DP de linfócitos que sofreram transformação blástica e, em (B), a média \pm DP do índice de proliferação, ambos obtidos por citometria de fluxo, conforme metodologia descrita por Machado-Jr. et al. (2006).

considerada marcadora de infiltração neutrofílica, corrobora com os nossos dados, confirmando e sugerindo uma atividade pró-migratória para este composto.

Um aspecto interessante com relação aos efeitos do ácido caurenóico sobre a migração de GNC humanos descritos pela primeira vez neste estudo é que, segundo Oliveira et al. (2002), esta substância constitui cerca de $10 \%$, em peso, do extrato de A. glabra. Neste sentido, observou-se para o grupo tratado com o extrato, uma resposta migratória negativa em relação ao gradiente, a qual, a $100 \mu \mathrm{g} / \mathrm{ml}$, foi semelhante à demonstrada pelo ácido caurenóico a $1,0 \mu \mathrm{M}$, sugerindo que o ácido caurenóico possa ser um dos compostos presentes no extrato responsável pelo efeito inibidor obtido.

Este diterpeno, por pertencer a uma classe de compostos que vêm, ao longo da última década, demonstrando diversidade de efeitos biológicos, têm sido alvo de várias modificações estruturais, com o objetivo de potencializar alguns dos efeitos descritos ou torná-los menos tóxicos ou, ainda, como protótipos para desenvolvimento de novas moléculas bioativas, aspectos esses amplamente explorados na revisão recente de García et al. (2007). Desse modo, a ausência de efeitos tanto para o extrato de A. glabra como para o ácido caurenóico com relação à atividade imunomodulatória corrobora com os relatos de Ohkoshi et al (2004), que demonstraram que somente os derivados hidroxilados nos carbonos 2, 3, 16 e 17 do ácido caurenóico obtido do extrato de Mikania hirsutissima, e os ácidos $2 \beta, 16 \alpha, 17-$ trihidroxi-ent-caurano-19-oico e 3 $\beta, 16 \alpha, 17$-trihidroxient-caurano-19-oico apresentaram significativa atividade imunomodulatória sobre linfócitos humanos.

A quimiotaxia, ou o movimento celular direcional, constitui-se de uma etapa fundamental dos processos que regulam e medeiam sincronicamente as respostas imune e inflamatória, e depende de um grupo de substâncias capazes de induzir uma locomoção direcional a favor ou contra um gradiente de concentração (Wilkinson, 1988). Se há uma resposta, é necessário que a célula em questão apresente pelo menos um receptor que permita o acoplamento deste ligante. Ou seja, tendo o ácido caurenóico demonstrado a capacidade de estimular a quimiotaxia de GNC humanos a favor de seu gradiente, implica que essas células são dotadas de um ou mais receptores responsáveis por esta interação.

Tirapelli et al. (2004) relataram que o ácido caurenóico tem a propriedade de interferir em vários mecanismos da resposta celular, sendo que um desses envolve a mobilização de $\mathrm{Ca}^{2+}$. Interessante ressaltar que a maioria dos receptores protéicos envolvidos na migração celular pertence à família de receptores associados ao complexo heterotrimérico da proteína $G$ e que, em regra, a transdução de sinal desses receptores se dá pela hidrólise do fosfatidil-inusitol 4,5-bifosfato em seus mensageiros intermediários, o diacilglicerol e o inusitol 1,4,5-trifosfato. Este, por sua vez, mobiliza as reservas de $\mathrm{Ca}^{2+}$, levando a um aumento transitório de $\mathrm{Ca}^{2+}$ intracelular (Ben-Baruch et al., 1995).

Portanto, é possível que os efeitos relatados neste estudo, tanto para o extrato de $A$. glabra como para o ácido caurenóico, sobre a migração de GNC humanos envolvam mecanismos relacionados ao fluxo de $\mathrm{Ca}^{2+}$, importante parte da cascata complexa da quimiotaxia, a qual depende do tipo celular envolvido, do ligante, da estrutura e configuração dos receptores, da proteína $\mathrm{G}$ envolvida e das diferentes enzimas-alvo que são ativadas no processo, além da possibilidade de, para o extrato de A. glabra em particular, devido à sua complexidade em termos de composição, serem resultantes da somatória de respostas moleculares causadas por cada um de seus constituintes isoladamente.

Assim, investigar os tipos de receptores celulares que interagem com o extrato de A. glabra e com o ácido caurenóico são necessários, não só para esclarecer os mecanismos de ação envolvidos, mas permitir que aplicações terapêuticas dessas substâncias sejam extraídas e direcionadas a disfunções concernentes à resposta inflamatória.

\section{AGRADECIMENTOS}

Os autores agradecem a Fundação Araucária/ PR, pelo apoio financeiro a F.H.R. 


\section{REFERÊNCIAS}

Alves TM, Chaves PP, Santos LM, Nagem TJ, Murta SM, Ceravolo IP, Romanha AJ, Zani CL 1995. A diterpene from Mikania obtusata active on Trypanosoma cruzi. Planta Med 61: 85-87.

Barroso GM, Guimarães EF, Ichaso CLF, Costa CG, Peixoto AL 1978. Annonaceae. vol. 1. São Paulo: LTC/ EDUSP.

Ben-Baruch A, Michiel DF, Oppenheim JJ 1995. Signals and receptors involved in recruitment of inflammatory cells. J Biol Chem 270: 11703-11706.

Block LC, Santos ARS, Souza MM, Scheidt C, Yunes RA, Santos MA, Monache F, Cechinel V 1998. Chemical and pharmacological examination of anti-conceptive constituents of Wedelia paludosa. J Ethnopharmacol 61: 85-89.

Boyden S 1962. The chemotactic effect of mixtures of antibody and antigen on polymorphonuclear leucocytes. $J \operatorname{Exp}$ Med 115: 453-466.

Cardoso-Lopes EM, Carreira RC, Agripino DG, Torres LMB, Cordeiro I, Bolzani VS, Dietrich SMC, Young MCM 2008. Screening for antifungal, DNA-damaging and anticholinesterasic activities of Brazilian plants from the Atlantic Rainforest - Ilha do Cardoso State Park. Rev Bras Farmacogn 18 (Supl.): 655-660.

Chang FR, Yang PY, Lin JY, Lee KH, Wu YC 1998. Bioactive kaurane diterpenoids from Annona glabra. J Nat Prod 61: 437-439.

Chen CH, Hsieh TJ, Liu TZ, Chern CL, Hsieh PY, Chen CY 2004. Annoglabayin, a novel dimeric kaurane diterpenoid, and apoptosis in Hep G2 cells of annomontacin from the fruits of Annona glabra. $J$ Nat Prod 67: 1942-1946.

Chen X, Oppenheim J, Howard OM 2001. Shikonin, a component of antiinflammatory Chinese herbal medicine, selectively blocks chemokine binding to $\mathrm{CC}$ chemokine receptor-1. Int Immunopharmacol 1: 229-236.

Costa-Lotufo LV, Cunha GM, Farias PA, Viana GS, Cunha KM, Pessoa C, Moraes MO, Silveira ER, Gramosa NV, Rao VS 2002. The cytotoxic and embryotoxic effects of kaurenoic acid, a diterpene isolated from Copaifera langsdorffii oleo-resin. Toxicon 40: 12311234.

Costa VCO, Tavares JF, Agra MF, Falcão-Silva VS, Facanali R, Vieira MAR, Marques MOM, Siqueira-Júnior JP, Silva MS 2008. Composição química e modulação da resistência bacteriana a drogas do óleo essencial das folhas de Rollinia leptopetala R. E. Fries. Rev Bras Farmacogn 18: 245-248.

Garcia PA, de Oliveira AB, Batista R 2007. Occurrence, biological activities and synthesis of kaurane diterpenes and their glycosides. Molecules 12: 455483.

Goody RJ, Kitchen I 2001. Influence of maternal milk on functional activation of delta-opioid receptors in postnatal rats. J Pharmacol Exp Ther 296: 744-748.

Hofbauer R, Frass M, Gmeiner B, Handler S, Speiser W, Kapiotis S 1999. The green tea extract epigallocatechin gallate is able to reduce neutrophil transmigration through monolayers of endothelial cells. Wien Klin Wochenschr 111: 278-282.
Hofbauer R, Frass M, Gmeiner B, Kaye AD, Frost EA 2001. Effects of garlic extract (Allium sativum) on neutrophil migration at the cellular level. Heart Dis 3: 14-17.

Ihantola-Vormisto A, Summanen J, Kankaanranta H, Vuorela H, Asmawi ZM, Moilanen E 1997. Antiinflammatory activity of extracts from leaves of Phyllanthus emblica. Planta Med 63: 518-524.

Lewis SL, Van Epps DE 1983. Demonstration of specific receptors for fluoresceinated casein on human neutrophils and monocytes using flow cytometry. Inflammation 7: 363-375.

Lima MRF, Ximenes CPA, Luna JS, Sant'Ana AEG 2006. The antibiotic activity of some Brazilian medicinal plants. Rev Bras Farmacogn 16: 300-306.

Mabberley DJ 1997. The plant-book. New York: Cambridge University Press.

Machado-Jr. J, Florão A, Mattana FVR, Rocha FH, Santos CAM, Weffort-Santos AM 2006. A citometria de fluxo como instrumento de avaliação da atividade imunomodulatória de extratos e substâncias isoladas de plantas medicinais. Rev Bras Farmacogn 16: 645655.

McCutcheon M 1955. Chemotaxis and locomotion of leukocytes. Ann N Y Acad Sci 59: 941-944.

Merchant D, Kahn R, Murphy W 1964. Handbook of cell and organ culture. Broken Arrow: Burgess Publishing.

Moreira IC, Roque NF, Contini K, Lago JHG 2007. Sesquiterpenos e hidrocarbonetos dos frutos de Xylopia emarginata (Annonaceae). Rev Bras Farmacogn 17: 55-58.

Muller AA, Reiter SA, Heider KG, Wagner H 1999. Plantderived acetophenones with antiasthmatic and anti-inflammatory properties: inhibitory effects on chemotaxis, right angle light scatter and actin polymerization of polymorphonuclear granulocytes. Planta Med 65: 590-594.

Nascimento AA, Ribeiro EAN, Oliveira JM, Medeiros FA, Silva MS, Medeiros IA 2006. Cardiovascular effects induced by the hydroalcoholic extract of the stem of Xylopia cayennensis in rats. Rev Bras Farmacogn 16: 17-21.

Ohkoshi E, Kamo S, Makino M, Fujimoto Y 2004. entKaurenoic acids from Mikania hirsutissima (Compositae). Phytochemistry 65: 885-890.

Oliveira BH, Sant'Ana AE, Bastos DZ 2002. Determination of the diterpenoid, kaurenoic acid, in Annona glabra by HPLC. Phytochem Anal 13: 368-371.

Padmaja V, Thankamany V, Hara N, Fujimoto Y, Hisham A 1995. Biological activities of Annona glabra. $J$ Ethnopharmacol 48: 21-24.

Page JE, Balza F, Nishida T, Neil Towers GH 1992. Biologically active diterpenes from Aspilia mossambicensis, a chimpanzee medicinal plant. Phytochemistry 31: 3437-3439.

Paiva LA, Gurgel LA, Silva RM, Tome AR, Gramosa NV, Silveira ER, Santos FA, Rao VS 2002. Antiinflammatory effect of kaurenoic acid, a diterpene from Copaifera langsdorffi on acetic acid-induced colitis in rats. Vascul Pharmacol 39: 303-307.

Presibella MM, Santos CAM, Weffort-Santos AM 2007. In vitro anti-chemotactic activity of Chamomilla recutita hydroethanol extract. Pharm Biol 45: 1-7. 
Presibella MM, Villas-Bôas LDB, Belletti KMS, Santos CAM, Weffort-Santos AM 2006. Comparison of chemical constituents of Chamomilla recutita Rauscher essential oil and its anti-chemotactic activity. Braz Arch Biol Technol 49: 117-724.

Ribeiro LAA, Tavares JF, Andrade NC, Silva MS, Silva BA 2007. O Ácido (8)17,12E,14-labdatrieno-18-óico (labdano302), diterpeno tipo labdano isolado de Xylopia langsdorffiana St. Hil. \& Tul. (Annonaceae) relaxa a traquéia isolada de cobaia. Rev Bras Farmacogn 17: 197-203.

Slimestrad R, Marston A, Mavi S, Hostettmann K 1995. Larvicidal constituents of Melantheria albinervia. Planta Med 61: 562-563.

Solymossy M, Nagy Z, Toth G, Antoni F 1986. Interaction of casein with human polymorphonuclear cells. Biochem Med Metab Biol 35: 293-301.

Tirapelli CR, Ambrosio SR, da Costa FB, Coutinho ST, de Oliveira DC, de Oliveira AM 2004. Analysis of the mechanisms underlying the vasorelaxant action of kaurenoic acid in the isolated rat aorta. Eur $J$ Pharmacol 492: 233-241.

Valter JL, Alencar KMC, Sartori ALB, Nascimento EA, Chang R, Morais SAL, Laura VA, Nídia Yoshida NC, Carollo CA, Silva DB, Grassi RF, Fabri JR, Siqueira JM 2008. Variação química no óleo essencial das folhas de seis indivíduos de Duguetia furfuracea (Annonaceae). Rev Bras Farmacogn 18: 373-378.

Velikova M, Bankova V, Tsvetkova I, Kujumgiev A, Marcucci MC 2000. Antibacterial ent-kaurene from Brazilian propolis of native stingless bees. Fitoterapia 71 : 693-696.

Vieira HS, Takahashi JA, Boaventura MA 2002. Novel derivatives of ent-17,19-dihydroxy-16,betaHkaurane obtained by biotransformation with Verticillium lecanii. J Agric Food Chem 50: 37043707.

Wilkinson PC 1988. Chemotactic factors: an overview. Methods Enzymol 162: 127-132.

Zhang YH, Peng HY, Xia GH, Wang MY, Han Y 2004. Anticancer effect of two diterpenoid compounds isolated from Annona glabra Linn. Acta Pharmacol Sin 25: 937-942. 